\title{
Visão da Criança sobre a Morte
}

\author{
CHILDREN'S VIEW ON DEATH
}

Juliana Vendruscolo

Docente. Universidade Paulista - UNIP. Universidade de Ribeirão Preto - UNAERP. Psicóloga do Grupo de Apoio à Criança com Câncer - GACC.

CoRRESPONDÊnCIA: Av. Meira Jr, no 1895 ap 302. 14085-230 Ribeirão Preto -SP. Telefone 0166240513 . e-mail: jvendruscolo@yahoo.com.br

Vendruscolo J. Visão da criança sobre a morte. Medicina (Ribeirão Preto) 2005; 38 (1): 26-33.

Resumo: Modelo de Estudo: Relato de casos. Objetivos do estudo: Rever alguns aspectos da literatura sobre a criança frente à morte integrando-os com experiências clínicas. A morte é algo desconhecido, inquieta-nos e leva a busca da compreensão do início e do fim. A criança vivencia questões relacionadas ao tema da morte e pode expressar sua experiência nessa realidade, cognitiva e afetivamente.Existem várias pesquisas sobre a compreensão da morte pela criança, relacionando essa compreensão com o nível de desenvolvimento global da criança. É possível identificar três componentes do conceito de morte na criança: irreversibilidade (impossibilidade de retornar ao estado anterior, morte do corpo), não funcionalidade (compreensão de que todas as funções definidoras da vida cessam com a morte) e universalidade (tudo que é vivo morre). Metodologia: Para ilustrar esses aspectos serão apresentados dois casos clínicos, o primeiro relacionado à vivência de agravamento de um câncer ósseo em uma criança de 5 anos e a possibilidade de morte iminente e o segundo direcionado para a vivência de luto de uma criança de 3 anos.Resultados. Conclusões: $O$ atendimento psicológico demonstrou ser imprescindível nas situações em que a criança vivencia questões relacionadas à morte. Importância do problema, Comentários: Os estudos sobre a compreensão da criança sobre a morte e o processo do morrer auxiliam os profissionais da saúde e também os familiares a lidar com a criança que experiência tal vivência, possibilitando que a mesma possa compartilhar seus sentimentos sentindo-se compreendida e acolhida.

Descritores: Morte. Crianças. Atendimento Psicológico. Luto.

\section{INTRODUÇÃO}

"Amar o perdido / deixa confundido /este coração.

Nada pode o olvido / contra o sem sentido / apelo do não.

As coisas tangíveis / tornam-se insensíveis / à palma da mão.

Mas as coisas findas / muito mais que lindas, / essas ficarão."

(Carlos Drummond de Andrade, "Memória").
A morte é algo desconhecido que nos inquieta, fazendo com que questionemos a vida em sua origem e seu fim. Como tema, já inspirou poetas e artistas em suas criações, as quais tocam nossa alma e nos aproxima, de forma delicada, dessa certeza tão temida em nossa existência.

Falar sobre a morte nos faz debruçar sobre o que permanece após a perda: a memória. Relembrando Alves ${ }^{1}$.

“...o que a memória ama fica eterno. Eternidade não é o sem-fim.

Eternidade é o tempo quando o longe fica perto.” (p. 43) 
Somos seres vivos mortais. Como humanos, nos diferenciamos de outros seres, justamente pela nossa consciência sobre a mortalidade, sobre a finitude de nossa existência. A certeza da morte é um dado que perpassa a nossa concepção sobre o homem. Segundo o filosofo Heidegger ${ }^{2}$ somos seres para a morte, e a vivência do tempo em harmonia circular do passado presente e futuro constitui o sentido de nosso existir.

Entretanto, essas reflexões parecem não nos respaldar, em um primeiro instante, quando vemos associados os termos morte e criança. Tais palavras parecem contraditórias. É como se a morte não se ocupasse da vida na infância em nenhuma forma de aproximação - pela morte da própria criança, pela perda de alguém próximo de sua convivência, ou de um bichinho de estimação ou até mesmo pelas imagens de TV e jogos infantis. Essa concepção errônea favorece atitudes inadequadas dos adultos com as crianças que vivenciam situações relacionadas à morte, tais como: evitar o assunto, minimizar o sofrimento que eles próprios estão sentindo para poupar a criança, utilizando eufemismos que confundem ainda mais a criança e até mesmo a criação de mentiras que venham substituir a situação que envolve a morte.

Segundo Kovács ${ }^{3}$

"Ao não falar, o adulto crê estar protegendo a criança, como se essa proteção aliviasse a dor e mudasse magicamente a realidade. $O$ que ocorre é que a criança se sente confusa e desamparada sem ter com quem conversar.” (p. 49)

O que será que uma criança pensa sobre a morte? Será que ela se preocupa mesmo com isso? Tais questionamentos que parecem perturbar os adultos precisam ser esclarecidos.

Torres ${ }^{4}$ refere que as investigações sobre a compreensão da morte pela criança começaram em 1934 e continuam ao longo desses anos diferenciando-se entre aquelas que questionam sobre a idade em que as crianças compreendem a morte e aquelas que, além disso, procuram investigar se a compreensão de cada componente está relacionada com o nível de desenvolvimento global. Essas dimensões de níveis do conceito de morte na criança São apresentados da seguinte forma:

- Irreversibilidade - impossibilidade de retornar ao estado anterior, morte do corpo.

- Não funcionalidade - compreensão de que todas as funções definidoras da vida cessam com a morte.

- Universalidade - tudo que é vivo morre.
Estudos psicoanalíticos também contribuem para compreensão sobre a maneira da criança conceber a morte Aberastury ${ }^{5}$ refere que a percepção da morte pela criança pode ser verificada respondendose a três questões:

- Como a criança expressa sua representação da morte? Que significados dá para ela?

- Percebe o perigo da morte quando está doente, com ou sem esperança de cura?

- Percebe a morte de pessoas queridas mesmo quando esse fato é omitido?

Os estudos realizados evidenciam, então, que a criança que vivencia uma situação relacionada à morte, seja a possibilidade de sua própria morte, ou mesmo a perda de pessoas queridas, mantém impressa em seu psiquismo, registros e emoções a esse respeito. A maneira como ela organiza e expressa sua compreensão e seus sentimentos está relacionada ao seu desenvolvimento afetivo e cognitivo. É imprescindível que para cuidar do psiquismo infantil os profissionais da saúde e os pais tenham como referência a moldura desenvolvimental, ou seja, que considerem o que é esperado em termos de habilidades e competências para cada faixa etária ${ }^{6}$. Será apresentada a seguir, uma descrição de alguns aspectos relacionados à temática da morte em 5 etapas do desenvolvimento, baseado em um estudo anterior com crianças curadas de câncer ${ }^{7}$. Vale ressaltar, que essa divisão das idades não deve ser considerada rigidamente, pois é possível ocorrer variações em diferentes crianças.

Um primeiro grupo a ser considerado envolve as crianças muito pequenas até os $\mathbf{3}$ anos de idade. O início desse período envolve aquisições básicas para o desenvolvimento, tais como o senso de confiança básica, que possibilita a criança visualizar o mundo como um lugar seguro e estável, adquirindo o sentido de confiabilidade, proteção e previsão em relação às outras pessoas e a si mesma. Nessa fase de exploração sensório-motora, as interações do bebê com o ambiente São governadas por sensações primitivas e atividades que gradualmente passam a ter o domínio motor. Por volta de 1 ano, o lactente já adquire a noção de que os objetos e pessoas são permanentes, existindo mesmo quando não estão no local. Posteriormente, começa a desenvolver a autonomia e o autocontrole. Há um aumento das habilidades motoras o que favorece maior independência dos pais. Essa criança, por volta dos 2 anos possui representações mentais do mundo, crescendo a possibilidade imaginativa e surgindo os pensamentos mágicos. As crianças que vivenciam uma perda nessa etapa, certa- 
mente sofrem o impacto da mesma, porém a comunicação de seu sofrimento pode ser incompreendida. Ela já sente falta de quem morreu, mas esse conceito abstrato não é apreendido. A pessoa não está mais ali, mas voltará, como outros saem e voltam. Entretanto, com o passar do tempo, a demora do retorno pode suscitar sinais de incômodo. Além desse aspecto, a criança nota a alteração emocional e até do cotidiano dos adultos com quem convive e, pelo processo, imaginativo, começa a buscar suas formas de compreender aquela situação.

No período compreendido entre 3 a 5 anos, as crianças já começam a serem desafiadas pelo mundo social a serem cada vez mais ativas, a dominar novas habilidades e serem mais produtivas. Precisam desenvolver um senso de iniciativa, conseguindo, assim, planejar e empreender tarefas com responsabilidade. Nessa fase o pensamento ainda é ilógico e egocêntrico. Os seus desejos exercem acentuada influência acerca da compreensão dos fenômenos do mundo. Frente à situação relacionada à morte já é possível ocorrer questionamentos sobre a causa, sendo que, devido ao egocentrismo, em muitas situações pode a mesma ser associada, em sua imaginação, à alguma de suas ações. Emerge o conceito de morte como imobilidade em contra posição ao de estar vivo, representado pelo movimento. Ainda há uma associação da morte com separação e sono, porém não de forma definitiva, mantendo a noção reversibilidade.

Por volta de 5 ou 6 anos, a vida escolar tornase mais intensa e sua importância aumenta, na medida em que é nesse ambiente que a criança aprimora seu senso de atividade, sentindo-se gratificada pelo sucesso e pela aquisição do senso de adequação e competência sobre si mesmas. Cognitivamente começa ocorrer a preocupação com regras, apesar do pensamento ainda ser concreto. A idéia de morte ainda não é universal, ou seja, não acontece a todos. Há uma tendência a personificar a morte e representá-las em figuras (bicho-papão, caveira...).

A noção de irreversibilidade começa a se instalar, bem como a concepção de quer não pode ser evitada. Há muita associação ao sono, a perda de consciência e gera um grande medo frente à separação, à obscuridade e ao vazio.

Entre 9 e 10 anos, em continuidade aos processos descritos anteriormente, as crianças já percebem que a morte envolve a cessação das atividades corpóreas e há diminuição do pensamento mágico. É capaz de incluir-se à idéia de morte, mas atribui o fim da vida à velhice e à doença.

\section{MATERIAL E MÉTODO}

Com o objetivo de ilustrar esses aspectos teóricos serão apresentados 2 casos clínicos referentes à vivência de 2 crianças frente à questão da morte. Esses casos foram atendidos no Serviço de Oncologia Pediátrica do Hospital das Clínicas da Faculdade de Medicina de Ribeirão Preto-USP.

A primeira criança, que chamarei de Gabriela, tem 3 anos de idade e perdeu sua irmã de 15 anos após um TMO há aproximadamente 6 meses.

O segundo caso contará a história de Maria, 5 anos, com diagnóstico de osteonarcoma em fase de agravamento da doença.

\section{RESULTADOS E DISCUSSÃO}

\section{Um pouco da história de Gabriela}

Gabriela iniciou o atendimento psicológico com 2 anos e 10 meses de idade. Sua Irmã de 15 anos (Isabela) havia falecido há 2 meses, após um transplante de medula óssea realizado para o tratamento de uma leucemia. Gabriela soube que a irmã estava com "dodói" e ia ao médico "tomar remédio" para sarar. Durante o período de tratamento, Gabriela ficava com as avós e amigas de sua mãe. Ela não foi informada sobre a morte da irmã no mesmo dia, sendo que posteriormente, foi dito a ela que sua irmã havia ido "mora com o papai do céu". Então, Gabriela passou a cobrar a volta da irmã para casa, pedindo para ir ao hospital buscá-la.

O primeiro atendimento foi realizado no hospital. Gabriela estava muito tensa e agitada. Aceitou brincar um pouco na recreação, mas logo que entramos na sala de atendimento ela começou a gritar, perguntando onde estava sua irmã. Kovacks ${ }^{3}$ menciona que em casos onde ocorre o ocultamento da verdade sobre a morte de pessoas da família o processo de luto da criança fica perturbado, bem como sua relação com o adulto. A criança percebe a incoerência do fato e das informações, sentindo-se confusa e frustrada se o adulto reforçar a primeira fase frente à perda, que é a negação, será difícil ocorrer a elaboração. Tentei perguntar-lhe sobre o que havia acontecido, mas Gabriela escondeu-se sob a mesa, recusando qualquer contato verbal e/ou físico. Procurei sinalizar-lhe que percebia seu descontentamento, sua irritação e sua vontade de ver a Isabela. Disse que estava ali para ajudá-la e que ela poderia ficar tranqüila. Ela ficou por mais ou menos 20 minutos no mes- 
mo lugar e ao sair pediu para ir embora. No dia seguinte falei com sua mãe ao telefone para saber como Gabriela estava. A mãe referiu que ela chorou ao sair do hospital e disse que não queria mais voltar lá. Combinamos o atendimento seguinte no consultório.

$\mathrm{O}$ segundo atendimento ocorreu de forma mais tranqüila. Gabriela entrou com sua mãe, explorou os brinquedos e gradativamente, ficou mais à vontade. Aceitou que a mãe saísse e ficamos a sós na sala de atendimento. Ela brincou com entusiasmo com a "fazendinha" e, repetidamente, fazia com que os bichos movessem. Então, a médica vinha e ele "acordava". Nesse momento é possível observar a idéia de reversibilidade da morte, associando-a com o dormir. Antes de ir embora pede para levar um camelo para poder cuidar dele em casa.

Não era o momento para intervenções, apenas era preciso que ela pudesse se expressar. Pedi para mãe para que marcássemos uma sessão de orientação. Nessa ocasião, expliquei-lhe sobre a necessidade de Gabriela falar sobre a morte. Sueli contou-me que isso ocorre em casa, mas que a família "muda de assunto". É importante notar, nesse aspecto, a dificuldade do adulto se deparar com essas questões

A mãe questiona se ela sabe mesmo o que houve e se não seria melhor "deixar de lado" esse assunto

A forma de abordar a necessidade de expressão de Gabriela sobre a morte da irmã foi direcionada pelos comportamentos de irritação e agressão apresentados pela criança e referidos pela mãe. Gabriela não aceitava limites, impedia que algum tocasse nos objetos de Isabela e recusava-se a usar a cama da irmã (transferida para ela no momento).

Frente a tais necessidades, Sueli concordou com a continuidade dos atendimentos. A alteração de comportamento demonstrava ser um sintoma desse processo de luto. Ainda não era possível compreender qual a sua representação sobre a morte, porém evidenciava-se que Gabriela sabia sobre a perda da irmã e sentia o impacto da mesma.

No $3^{\circ}$ e $4^{\circ}$ atendimento, Gabriela manteve as brincadeiras com a "fazendinha", sendo que os animais adoeciam e morriam, mas com a presença do médico, acordavam e voltavam a viver. Entretanto, começou a expressar sentimentos que oscilavam entre raiva e tristeza em relação ao animal morto. Quando pontuava que percebia sua raiva, Gabriela dizia: "Porque morreu? A Gabriela ta aqui... ele não quer mais brincar, foi embora no hospital e não voltou".. Em seguida gritava com o bichinho: "Bobo, bobo".. E fala- va: "A Gabriela ta triste, vai chorar". A possibilidade de expressar os sentimentos ajudou Gabriela a se aproximar da sua experiência frente à morte de sua irmã. Iniciam os questionamentos e a busca de soluções concretas (a médica vem e resolve).

Então desenhava a carinha de feliz. Nessa ocasião falou de Isabela, dizendo que ela havia ensinado a desenhar. Perguntei sobre Isabela e ela disse que o "papai do céu" quis morar com ela. "Não voltou mais".. Em seguida correu até a janela, olhou para o céu e disse: "A Isabela! Ta no céu. Olha lá... Ela ta vindo aqui. Vem brincar com a Gabriela"..

Permanecer na dor, falar da tristeza se torna difícil, é preciso a "carinha de feliz". Começam a emergir as lembranças, porém nessa fase, misturados à realidade.É possível observar a dificuldade quanto à noção de irreversibilidade.

Após esse $3^{\circ}$ atendimento Sueli relatou que Gabriela estava um pouco mais tranqüila em casa, dormindo melhor e não havia mais pedido para buscar Isabela no hospital.

No $4^{\circ}$ atendimento Gabriela retoma a brincadeira com a "fazendinha", os desenhos da carinha e começa a montar lego. Com o lego faz sua família e diz que a Isabela veio no consultório para me ver. Pede para que eu a cumprimente. Conversamos sobre ela, o que estava fazendo ali e procuro favorecer que Gabriela expresse seus sentimentos. "O papai do céu deixou ela vir me ver. Ali a Isabela...”.

Após alguns minutos ela pergunta: "A moça quer saber se ela pode sentar no sofá branco".. Quando peço para explicar quem é a moça, ela diz que é uma moça que morreu ontem e veio com a Isabela. Diz que ela quer ficar um pouco no sofá. Pede para que eu olhe. É preciso mergulhar no mundo imaginativo desta criança para estar com ela em seus sentimentos. Há uma identificação muito forte com a irmã e, nessa fase, cuidar de sua volta parece ser uma tarefa importante. Kovacks ${ }^{3}$ citando Raimbault refere que a elaboração do luto exige uma desindentificação e um desinvestimento de energia que permita a introjeção do objeto perdido na forma de lembranças, atos, palavras e até em o investimento de energia em outro objeto. Contudo, esta parece ser uma árdua tarefa nessa etapa da vida.

Olho na direção que ela indica e digo que tem algumas coisas que eu não vejo, mesmo ela conseguindo ver, mas que ela pode dizer para a moça ficar, se ela concordar. Ela "fala" com a moça. Pergunta se ela conhece essa pessoa e ela diz que não. Mostro que ela tem conseguido falar comigo sobre gente que 
morre, sobre saudade e sobre a Isabela alguns minutos despede-se da moça. Sueli continua referindo melhora do comportamento.

No $5^{\circ}$ atendimento Gabriela estava tranqüila, brinca com a "fazendinha", devolve o camelo e diz que a Isabela não vem porque está com o "papai do céu".

Ela parece sinalizar sua integração,o camelo já está bom, pode voltar para o consultório e Isabela aparece situada de uma forma mais integrada

Em 07, retomamos os atendimento a pedido da mãe, pois Gabriela passa a incluir a presença da irmã nas refeições da família. Frente a esta atitude, a mãe concorda que Isabela virá e depois evita a continuidade do assunto. Sueli queixa-se que Gabriela parece imitar a irmã, o que a deixa irritada com a criança. Segundo Bromberg 8 é preciso considerar as relações familiares da criança enlutada, pois todo funcionamento do sistema familiar pode estar alterado. A autora prossegue afirmando que de acordo com vários teóricos, $\mathrm{o}$ primeiro passo para a elaboração do luto é a aceitação que a morte se deu. Entretanto, muitas famílias não compreendem a forma da criança pequena aceitar esse fato por não entenderem o funcionamento do psiquismo infantil.

Nos atendimentos Gabriela mostra-se agressiva. Falo sobre a morte dos bichos, mas recusa-se a falar da irmã.

Em nosso $8^{\circ}$ atendimento Gabriela chega sorridente e logo vai à janela. Pede para abrir e quer olhar o céu.

Proponho desenho. Peço que desenhe sua casa e as pessoas que moram lá. Ela diz que não e que vai desenhar um coração feliz. Falo sobre ela estar feliz hoje. Ela sorri. Diz que às vezes fica triste e faz coração triste. Pergunto sobre o porque está triste e ela conta sobre briga com sua mãe. Ela já consegue falar de tristeza e pela primeira vez a desenha. Então pontuo que às vezes isso acontece e pergunto o que houve com ela. "Minha mãe me bateu... não eu bati nela porque ela pegou o meu sapato... aí ela chorou e ficou triste".. Procurei abordar com ela as situações onde a gente faz coisas que os adultos não gostam e eles também brigam. Ela ia falar sobre a Isabela parou. "A I..." "O que foi? O que você ia contar..." "Nada, a Isabela não tá".. Falo sobre lembrar da irmã, da saudade, da vontade de vê-la e da raiva que dá quando ela não está. Ela desenha uma pessoa mas quer parar de "brincar disso".

Pede o "Rei Leão", brinca com ele e os demais bichos. Ele morre e outro animal o carrega. "Agora vai levá ele... Pronto, levou... Agora acordou... Vamos pegar a cavala agora...". Tento questionar para onde levaram ele, mas Gabriela parece não querer falar sobre isso. Faz a mesma brincadeira com a "cavala", mas não responde à questões. Então digo a ela que os bichinhos morreram e foram levados para outro lugar e aí a gente não vê onde é. "E". Brincamos com uma árvore e frutinhas para montar e encaixar, dando nomes às frutas (pêra, maçã, laranja e limão). Agora eu sou eu sou a "Branca de Neve". Anda pela sala como se visse as camas dos 7 anões. Pega a maçã "É a maça miraculosa..." "come" a maçã e cia no chão "Morri". Repete essa cena várias vezes e em seguida faz a Cinderela morrer. "Ela cai, fica doente e morre".. Também repete a cena várias vezes.

"Quanta gente e bicho que morreu não é Gabriela?" "A Isabela não vem" "Ela não vem, também morreu".

Ela corre para a janela para fechar a cortina. Nesse momento a mãe interrompe a sessão. Encerro com Gabriela.

Gabriela continua em atendimento psicológico bem como sua mãe e a sua irmã mais velha também. O pai recusou o acompanhamento, mantendo, em casa, total silêncio frente a seus sentimentos.

O caso de Maria será apresentado da maneira mais próxima ao seu jeito de ser - contando uma história.

\section{A CAIXA DE SEGREDOS}

Era uma vez, uma menina chamada Maria. Ao longo dos seus 3 anos, algumas coisas importantes demarcaram sua vida, como por exemplo: ser fã incondicional da cantora Sandy; namorar o irmão da mesma, Júnior; decidir tornar-se jogadora de vôlei e a descoberta de um osteonarcoma em seu braço. Toda a sua família, que não era aquela que chamamos de nuclear, envolveu-se no processo de tratamento. As presenças marcantes eram de sua mãe, companheira para mimos e broncas, sua avó que sempre tentava convencer o mundo a seu favor e seu tio, que mais tarde veio a ocupar o papel de pai, ausente até então.

Foram muitos sufocos ao longo do tratamento: possibilidade de amputação do braço, quimioterapia, recidiva na perna, nova cirurgia e mais quimio. Maria e sua mãe sempre firmes e, participando das decisões, superavam cada obstáculo. E foi assim, com essa mesma determinação que fizeram a outra parte da história que recomeçou quando a quimioterapia já não tinha mais um bom 
resultado sobre o tumor, as dores aumentavam e surgiram as metástases.

A gente se encontrava quando Maria vinha ao hospital para a consulta médica. Essas "conversas" com a "tia" dependiam da vontade de Maria. Nessa época em que não era mais possível andar e ela ficava em um carrinho, era muito importante respeitar seus sinais verbais ou gestuais quando indicavam a recusa de contato ou desejo de aproximação. A indicação de quimioterapia e radioterapia paliativa, deixando margem para a ansiedade da mãe, frente a dúvida: fazer ou não? Deixá-la "sossegada"? Era importante ouvir Maria, mas entendê-la em sua linguagem de 5 anos. Ela queria viver intensamente um monte de sonhos, aceitava tratar-se para conseguir realizá-los, mas precisava estar em sua casa, com suas coisas...

Segundo Kovácks ${ }^{3}$ as crianças percebem a deterioração que a doença provoca, pois elas estão em contato intimo com o próprio corpo. Podem chegar até a fazer perguntas, porém, procurando a confirmação de algo que já sabem.

Optou por radioterapia para amenizar a dor, analgesia com controle por medicamentos e interrupção da quimioterapia. Porém, os "carocinhos" continuavam a aparecer e incomodavam Maria e sua mãe, que preocupava-se em poupá-la de tal constatação. O mais interessante é que Maria também queria cuidar de sua mãe e controlava-se ao máximo para não expressar sentimentos que a entristecessem. Foi aí que criamos o artifício da "cai$x a$, de segredos". Lá cabia tudo, os sonhos, os medos, os amores e os "combinados" (pactos entre nós duas). Cuidávamos da nossa caixa, concretizando em uma caixa de sapatos embrulhada em papel colorido, ao som de "Sandy e Júnior". Um dia, ao longo das nossas "conversas" Maria pediu para abrir a caixa pois iríamos guardar mais segredos. Ela disse:

M - "Tia, vou colocar uma música que você gosta”. Localizou no CD a música "Inesquecível". Ouvimos. Em seguida disse:

$M-$ "Você sabe o que é inesquecível?"
$T-$ "O que é pra você??".
$M-$ "É o que a gente não esquece".
$T-$ "É, acho que é isso".
$M-$ - Quando a gente gosta de alguém, esse alguém, ele mora no coração da gente e é inesquecível...”. Sabe tia, minha mãe não entende essa música.
$T$ - "Por quê??".

$M$ - "Ela acha que não tem jeito de ser inesquecível”.

Maria volta-se para o CD e escolhe a música "Imortal". Ouvimos e cantamos.

$M$ - "Tia, sabe o que é imortal?".

$T$ - "Me conta".

$M$ - "É o que não morre... pode ir embora mas fica no coração. Que nem inesquecível. Quando a gente gosta é imortal pro outro e fica assim, sem esquecer".

$T$ - "Isso que você está falando é muito bonito, emociona a gente".

$M$ - "Eu sou imortal pra você e você não me esquece e você é também para mim. Quando a gente gosta uma da outra, você cuida dos meus segredos. Tia, ajuda minha mãe a entender a música. Ela é teimosa. Acho que se eu for embora com o Júnior ela vai ficar mal...".

Conversamos sobre esses sentimentos, sobre a nossa emoção naquela hora e o quanto queremos cuidar de quem amamos. Um combinado daquele dia foi que eu a ajudaria a fazer sua mãe entender "essas coisas". Ela pede para levar a caixa de segredos para a sua casa.

Kovácks ${ }^{3}$ refere que as crianças terminais, além do medo da morte apresentam medo do sofrimento, do tratamento e da separação. É muito importante que a criança que estiver com a possibilidade de morte iminente sinta-se acompanhada. O medo da morte como finitude ainda não está presente aos 5 anos. Entretanto a ameaça do rompimento de laços afetivos com as figuras de apego mantêm-se como ponto comum desde etapas anteriores ${ }^{8}$. A percepção do agravamento favorece que a criança consiga integrar-se com mais facilidade ao processo de despedida ${ }^{8}$. É preciso entender a linguagem que ela usa para nos sinalizar essa vivência.

Assim eu fiz. Nesse mesmo sentido, conversei com sua mãe. Foram novos momentos dificeis. A doença progredia. Maria ficou cega e cada vez mais, enxergava de longe os acontecimentos. Aproximei-me ainda mais de sua mãe, ajudando-a a estar ao lado de Maria o tempo necessário.

Uma semana após a sua morte, sua mãe ligou e disse que precisava me ver. Marcamos uma "conversa" para o dia seguinte.

Ao chegarem ao hospital, a mãe, a avó e o tio emocionaram-me, porém conseguiram permanecer no hospital. 
A mãe entrega-me a caixa de segredos e diz que Maria uma semana antes de seu agravamento, havia pedido para avó guardar a caixa e entregá-la para mim. Antes, abriu-a e mostrou alguns objetos, dizendo que os segredos sempre iam existir. Disse que a mãe e a avó tinham que me entregar a caixa.

Eu acho que Maria sabia que a entrega da caixa de segredos ia favorecer que a mãe e a avó também compartilhassem alguns, naquele momento.

Falamos de muitas coisas, relembramos os bons momentos, os difíceis também, contaram sobre "Eu não fiz tudo o que eu podia...". Levantamos os "se" e os "será". Enfim, foi possível expor tudo aquilo que se tenta prender em um processo de luto.

Alguns meses depois, sua mãe ligou e contou sobre novos projetos, confirmando o nosso grande e precioso segredo sobre algo como "Inesquecível" e "Imortal".

\section{CONCLUSÃO}

Falar sobre a morte pode nos trazer temores, criar angústia e resultar em uma vontade de evitar o assunto. Entretanto ela é uma parte da nossa vida. Como profissionais da saúde precisamos de recursos para lidar com essas situações e assim, continuar cuidando de nossos pacientes. Ainda recorrendo à poe- sia, recorro novamente a Alves (19981) que descreve essa possibilidade em uma especialidade por ele criada e denominada "morienterapeuta" (moriens - que está morrendo (latina) e therapeuein - cuidar, servir, curar (do grego)).

“ O morienterapeuta, ao contrário, entra em cena quando as esperanças se foram. A despedida é certa. Ele ou ela tem de estar em paz com a vida e a morte, tem de saber que a morte é parte da vida: precisa ser cuidada. Por isso, o morienterapeuta terá de ser um ser tranqüilo, em paz com o fim, com o fim dos outros de quem ele cuida, em paz com o seu próprio fim, quando outros cuidarão dele. Dele não se esperam nem milagres nem recursos heróicos para obrigar o débil coração a bater por mais um dia. Dele se esperam apenas os cuidados com o corpo - é preciso que a despedida seja mansa e sem dor. E os cuidados com a alma: ele não tem medo de falar sobre a morte.”(p.132-133)

Quem sabe assim, poderemos, em sintonia com o poeta, dizer:

“ Compreendi, então, que a vida não é uma sonata que, para realizar a sua beleza, tem de ser tocada até o fim. Dei-me conta, ao contrário, de que a vida é um álbum de minissonatas. Cada momento de beleza vivido e amado, por efêmero que seja, é uma experiência completa que está destinada à eternidade. Um único momento de beleza e amor justifica a vida inteira."(p.139)

Vendruscolo J. Children's view on death. Medicina (Ribeirão Preto) 2005; 38(1): 26-33.

Abstract: Type of Study: Cases Report. Study's Objectives: To review some aspects in literature about the children's view on death, integrating them with clinical experiences. Death is something unknown that disturb us and lead us to a search for the comprehension of the beginning and of the end. Children experience situations that are related to the topic of death and they can express their experiences in this reality, cognitively and affectionately. There are several researches into the children's comprehension of death, relating this comprehension with the children's level of global development. It is possible to identify three components in the children's death concept: irreversibility (impossibility to return to the previous state, body's death); no functionality (understanding that all functions that define life cease with death) and universality (everything that is alive, dies). Methodology: In order to illustrate these aspects two clinical cases will be presented: the first one is related to the experience of a five-year-old child with bone cancer, whose disease grew worse with the possibility of imminent death and the second one is directed to a three-yearold child's mourning experience. Results and Conclusion: The psychological assistance proved to be indispensable when children experience situations that are related with death. Problem's importance and Comments: The studies of the children's comprehension of death and of the dying process help the health professionals and also the families to deal with those children who go through such experience, making it possible for them to share their own feelings and at the same time to feel understood and protected.

Keywords: Death. Children. Psychological Assistance. Mourning Experience. 


\section{REFERÊNCIAS BIBLIOGRÁFICAS}

1 - Alves R. Concertos para corpo e alma. Campinas:Papirus; 1998. p.132-3.

2 - Heidegger M. Ser e tempo I, II.Petrópolis: Vozes; 1996.

3 - Kovácks MJ. Morte e desenvolvimento humano. São Paulo:Casa do Psicólogo; 1992.

4 - Torres WC. A criança diante da morte. Desafios. São Paulo:Casa do Psicólgo; 1999.

5 - Aberastury A. La percepcion de la muerte en los niños y otros escritos. Buenos Aires: Kargieman; 1978.
6 - Greenspan S. Entrevista clínica com crianças. Porto Alegre: Artes Médicas;1993.

7 - Vendruscolo J, Valle EMR. A criança curada de câncer, modos de existir. In: Valle ERM, org. Psico-oncologia pediátrica. São Paulo: Casa do Psicólogo;2001. p. 247-292

8 - Bromberg MHPF. "Ele vai voltar?" A criança diante da morte. In: Berthoud CME, Bromberg MHPF, Borrego MRMC. Ensaios sobre formação e rompimento de vínculos afetivos. Taubaté:Cabral Editorial;1997. p. 43-63. 